\title{
Surface flow types, near-bed hydraulics and the distribution of stream macroinvertebrates
}

\author{
M. A. Reid and M. C. Thoms \\ Riverine Landscapes Research Lab, Faculty of Applied Sciences, University of Canberra, Australia \\ Received: 12 February 2008 - Published in Biogeosciences Discuss.: 12 March 2008 \\ Revised: 24 June 2008 - Accepted: 24 June 2008 - Published: 28 July 2008
}

\begin{abstract}
Spatial variation in hydraulic conditions in streams often results in distinct water surface patterns, or surface flow types. Visual assessments of the distribution of surface flow types have been used to provide rapid assessment of the habitat heterogeneity. The efficacy of this approach is predicated on the notion that surface flow types consistently represent a distinct suite of hydraulic conditions with biological relevance. This study tested this notion, asking three specific questions. First, do surface flow types provide a characterisation of physical habitat that is relevant to macroinvertebrates? Second, how well do near-bed hydraulic conditions explain macroinvertebrate distributions? Third, what components of near-bed hydraulic conditions exert the strongest influence on macroinvertebrate distributions?

Results show that hydraulic conditions (incorporating direct measurements of near-bed velocity and turbulence in three dimensions) and substratum character (incorporating estimates of particle size distribution, and biofilm and macrophyte cover) within each surface flow type were largely distinct and that macroinvertebrate assemblages differed across flow types in taxon richness and assemblage composition, thus supporting the notion that rapid assessments of surface flow type distributions provide biologically relevant information.
\end{abstract}

Macroinvertebrate assemblages were most strongly correlated with water depth, size of a flow type patch, near-bed velocity in the downstream direction, turbulence in the transverse direction, $\%$ pebble, $\%$ sand, $\%$ silt and clay and macrophyte cover. This study suggests that surface flow type mapping provides an assessment of physical habitat that is rele-

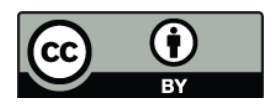

Correspondence to: M. A. Reid (mike.reid@canberra.edu.au) vant to macroinvertebrates. The strong relationship detected between macroinvertebrate assemblages and transverse turbulence also highlights the value of directly measuring nearbed hydraulics. Further investigations are required to test the mechanisms underlying this relationship.

\section{Introduction}

Flow is of fundamental importance to aquatic biota (Davis and Barmuta, 1989; Growns and Davis, 1994; Quinn and Hickey, 1994; Hart and Finelli, 1999; Finelli et al., 2002; Biggs et al., 2005; Brooks et al., 2005). Hydraulic conditions influence biota directly, by exerting stresses that limit access and utilisation of habitat (Davis, 1986) and through the influence on the supply of particulate food resources, dissolved gases and nutrients for metabolic processes (Quinn et al., 1996; Robson et al. 1999; Biggs et al., 2005). Hydraulic conditions also influence stream biota indirectly by creating, modifying and eliminating physical habitat (Biggs et al., 2005). In conjunction with the nature of the river-bed substratum, which itself influences and is influenced by hydraulic conditions (Davis and Barmuta 1989; Young, 1992; Rempel et al., 2000; Emery et al., 2003), the range of hydraulic conditions present within a stream is fundamental to the physical habitat template affecting all instream biota (Hart and Finelli, 1999; Rempel et al., 2000).

Water depth, roughness and slope are the principal determinants of hydraulic conditions within river channels. Variation in these parameters results in spatial and temporal heterogeneity in hydraulic conditions. Where gradients are sufficiently large, this heterogeneity results in clear differences in water surface features known as "surface flow types". Eight different surface flow types have been

Published by Copernicus Publications on behalf of the European Geosciences Union. 
described Padmore (1998), each distinguishable by visual assessment. The strong influence of hydraulic conditions on biota, along with the visually distinct nature of surface flow types, has led to their use for rapid assessment of physical habitat heterogeneity in streams. This approach is based on the argument that the mosaic of surface flow types within a stream equates to a mosaic of mesohabitat patches (Newson and Newson, 2000; Dyer and Thoms, 2006). The efficacy of this approach is, therefore, predicated on the notion that these surface flow types represent a distinct suite of hydraulic conditions with biological relevance.

Individual surface flow types are hydraulically different with distinct Froude numbers (Padmore, 1998). However, the significance of surface flow types for benthic organisms, which are influenced directly by near-bed hydraulic conditions rather than the surface expression of water column hydraulics, is less clear. Although near-bed hydraulic conditions can be inferred to a degree through depth-velocity relationships, the accuracy of these inferences is reduced in shallow water and where roughness elements are more varied (Young, 1992; Rempel et al., 2000). Benthic animals also have behavioural characteristics that may reduce the importance of ambient water column hydraulic conditions in determining their distributions. The capacity of macroinvertebrates to burrow to avoid hydraulic stress during spates, for example, will reduce the influence of water column hydraulics on benthic fauna and hence contribute to mismatches between the surface manifestation of near-bed hydraulic conditions and benthic faunal assemblages.

Field measurements of water depth, velocity, bed roughness and water surface slope can be used to characterise nearbed hydraulic conditions (Davis and Barmuta, 1989; Young, 1992); however, these measurements are substantially more time consuming than simple visual identification of surface flow types. Thus, if strong relationships between surface flow types, near-bed hydraulic conditions and macroinvertebrate assemblages could be demonstrated the task of characterising hydraulic habitat as it relates to benthic macroinvertebrates would become more straightforward and rapid.

Empirical evidence of the biological significance of surface flow types is limited. However, Grundy (1996) did report that while water quality factors such as $\mathrm{pH}$, conductivity and temperature may drive benthic invertebrate patterns at regional scales, physical variables describing surface flow types were strongly related to macroinvertebrate assemblages at local or reach scales. In addition, Reid et al. (2006) found rates of respiration in biofilms on cobbles from areas of no perceptible flow differed from that on cobbles from areas of rippled flow and broken standing wave flow; however, no differences were detected in metabolism between the latter two flow types. The degree to which surface flow types represent distinct mesohabitat patches relevant to biota will determine the effectiveness of these features as proxies for physical habitat heterogeneity, and by extension, biological diversity.
This study examines the distribution of macroinvertebrates in an upland stream across a range of surface flow types. It differs from previous studies in that near-bed hydraulic conditions are measured directly, rather than inferred from measurements higher in the water column, and that these measurements incorporate measures of velocity and turbulence in three dimensions. Our aim is to answer three questions in relation to macroinvertebrate distributions, surface flow types and near-bed hydraulic conditions. First, do surface flow types provide a characterisation of physical habitat that is relevant to macroinvertebrates? Second, to what extent do near-bed hydraulic conditions explain macroinvertebrate distributions? Third, what components of near-bed hydraulic conditions exert the strongest influence on macroinvertebrate distributions?

\section{Methods}

\subsection{Study area}

The Cotter River is an upland cobble/gravel bed river in the eastern highlands of Australia (Fig. 1). The study reach is a fourth order stream that spans an altitudinal range from $700 \mathrm{~m}$ to $500 \mathrm{~m}$ above-mean sea-level; its catchment is largely unmodified by humans with $88 \%$ contained within the Namadgi National Park. The underlying geology is a mix of granite, limestone, siltstone and shale; catchment topography is steep with rock outcrops common, particularly at higher altitudes. The climate is temperate with hot summers and cold winters. Average precipitation ranges from $990 \mathrm{~mm}$ to $1080 \mathrm{~mm}$ with the wettest months being between July and October.

Three dams that supply water for the city of Canberra (pop. 322 000) regulate flow in the river. During the spring and summer months leading up to data collection, environmental flow releases, in the form of short flow pulses, were made. The principal aims of these releases were twofold; firstly, to limit algal biomass, algae being thought to be advantaged by the low and relatively constant flow that would have otherwise persisted under the regulated regime; and secondly, to remove fine sediments from riffle areas, which are prone to deposition of fine materials since major fires burnt most of the catchment in 2003 (Norris and Thoms, 2004).

Sites included in the study are all situated between the second and third dams in the three dam sequence. Sampling for this study all took place during a period of low flow when releases from the upstream dam ranged from $0.51 \mathrm{~m} \mathrm{~s}^{-3}$ to $0.21 \mathrm{~m} \mathrm{~s}^{-3}$. The most recent environmental flow release from this dam, which peaked at $1.74 \mathrm{~m} \mathrm{~s}^{-3}$, ended 11 days prior to the first sampling. 


\subsection{Study design}

The study was carried out over a two-week period in February 2006. Six of the eight flow types listed in Table 1 were included in the study: no perceptible flow (NPF), smooth surface turbulent (SST), rippled flow (RF), unbroken standing wave (USW), broken standing wave (BSW) and chute flow (CF). These were determined prior to sampling based on previous studies (Dyer and Thoms, 2006). Two flow types - upwelling flow and free fall - were omitted from the study because they were either rare or absent within the study reach.

Benthic macroinvertebrates were sampled in five replicate patches of each of the six flow types using a Surber sampler ( $250 \mu \mathrm{m}$ mesh, $900 \mathrm{~cm}^{2}$ opening). Three Surber samples were taken in each surface flow type patch and amalgamated, meaning that a total of $0.27 \mathrm{~m}^{2}$ was sampled in each patch. Subsamples of 200 individuals from each replicate were then "live picked" in the field using a 100-cell sub-sampler which allowed for the proportion of the total sample counted to be calculated. Where less than 200 individuals could be found in a sample, the entire sample was picked. Macroinvertebrate densities were thus calculated by multiplying the final count by the proportion of the sample counted.

Macroinvertebrates collected from each sample in the field were subsequently identified in the laboratory to family level. The exceptions to this were Chironomidae, which were identified to subfamily level, and Oligochaeta and Nematoda, which were not resolved beyond class. Taxa were subsequently assigned to functional feeding groups based on the literature and taxonomic guides (Chessman, 1986; Gooderham and Tsyrlin, 2002) and consultation with experts (J. Hawking and R. Butcher).

Prior to macroinvertebrate sampling, the area (in $\mathrm{m}^{2}$ ) of the patch to be sampled was estimated. Estimates were also made within each patch of the percent cover of bedrock, boulder, cobble, gravel, sand, and combined silt/clay and of the percent cover by diatoms, filamentous green algae and macrophytes. The near-bed hydraulic conditions within each patch were characterised by a series of 6 near-bed flow measurements taken using a SonTek FlowTracker Handheld ADV at positions located randomly within each patch. All measurements were taken at $1 \mathrm{~cm}$ above the bed and individual velocity measurements were recorded in 3 dimensions at one-second intervals for at least $60 \mathrm{~s}$. Signal-to-noise ratios were checked at the end of each measurement period with data runs having ratios below 10 being rejected (Sontek, 2002). Data were also rejected if major boundary adjustments were made by the instrument (Sontek, 2002). The accepted data were used to derive mean velocity in 3 dimensions for the 60-s period as well as the variance in these velocity measurements over the period. The $3-\mathrm{D}$ variance measures were used to infer turbulence in each dimension and also summed to infer total turbulence for each individual measurement (Nikora and Goring, 1998).

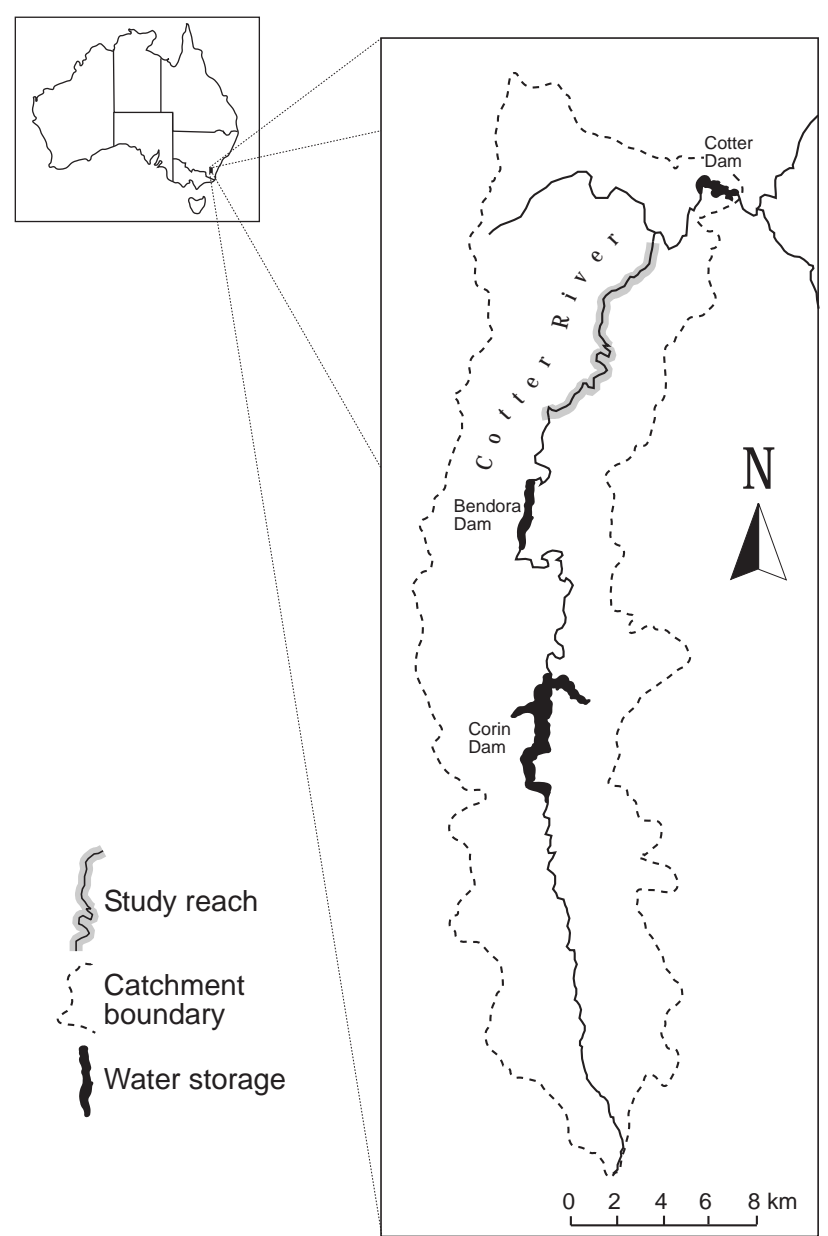

Fig. 1. The Cotter River catchment with the study reach indicated by grey shading.

\subsection{Data analysis}

Between surface flow-type differences in near-bed hydraulic variables, taxon richness, invertebrate density per $\mathrm{m}^{2}$ and diversity were tested initially using single factor ANOVA with dependent variables transformed where appropriate to fulfil the requirements of even variance between groups. In addition, relationships between dependent macroinvertebrate variables and explanatory variables such as 3-D flow velocity, turbulence, substrate type and algal and macrophyte cover were examined using scatterplots and regression calculated using SPSS (SPSS 14.0 for Windows, 2005).

Multivariate analyses were applied to compare surface flow patches according to their hydraulic character (incorporating 3-D near-bed velocity and turbulence measures, depth and Froude number), substratum character (incorporating substratum texture, along with biofilm, filamentous algae and macrophyte cover) and macroinvertebrate assemblages. Differences in the hydraulic and substratum characters of each flow type were tested with ANOSIM in the Primer computer 
Table 1. Surface Flow Types used to assess the hydraulic character of the stream (after Newson and Newson, 2000).

\begin{tabular}{|c|c|c|}
\hline Flow Type & Abbreviation & Definition \\
\hline No Perceptible Flow & NPF & $\begin{array}{l}\text { Smooth surface, suspended matter and surface foam appears stationary. A stick placed on } \\
\text { the waters surface remains still. }\end{array}$ \\
\hline Smooth surface turbulent* & SST & $\begin{array}{l}\text { Flow in which relative roughness is sufficiently low that very little surface turbulence } \\
\text { occurs. Very small turbulent flow cells are visible, reflections are distorted and surface } \\
\text { foam moves in a downstream direction. A stick placed vertically into the flow creates an } \\
\text { upstream facing "V". }\end{array}$ \\
\hline Rippled Flow & $\mathrm{RF}$ & $\begin{array}{l}\text { The water surface has regular disturbances, which form low transverse ripples across the } \\
\text { direction of flow. Ripples generally move in a downstream direction. }\end{array}$ \\
\hline Unbroken Standing Waves & USW & Undular standing waves in which the crest faces upstream but there is no broken water. \\
\hline Broken Standing Waves & BSW & $\begin{array}{l}\text { Standing waves present which break at the crest (white water). The crest faces an up- } \\
\text { stream direction. }\end{array}$ \\
\hline Free Fall & $\mathrm{FF}$ & $\begin{array}{l}\text { Water falls vertically without obstruction from a distinct feature. Generally more than } 1 \mathrm{~m} \\
\text { high and often across the full channel width. }\end{array}$ \\
\hline Chute Flow & $\mathrm{CF}$ & $\begin{array}{l}\text { Fast, smooth boundary turbulent flow over boulders and bedrock. Flow is in contact with } \\
\text { the substrate, and exhibits upstream and convergence and downstream divergence. The } \\
\text { flow is typically being funneled between macro bed elements. }\end{array}$ \\
\hline Upwelling & UF & $\begin{array}{l}\text { The direction of flow is predominantly vertical with strong horizontal eddies; boil forms } \\
\text { on the surface of the water or circular horizontal eddies are visible. }\end{array}$ \\
\hline
\end{tabular}

*referred to in Newson and Newson (2000) as "smooth boundary turbulent".

program (Version 6.1.5, Primer-E 2006) based on Gower dissimilarity matrices, as recommended by Belbin and McDonald (1993) for non-biological data. Differences in the macroinvertebrate assemblages of each flow type were also tested with ANOSIM, based on a similarity matrix of BrayCurtis similarity measures calculated from square root transformed taxon abundance data. The statistical significance of differences between groups can be determined using this procedure; however, this may be low due to small sample sizes, so it is useful to also compare the R-values themselves, since these provide an absolute measure of between group separation (Clarke and Gorley, 2001). Accordingly, values in excess of 0.75 indicate groups are well separated, values between 0.5 and 0.75 indicate overlapping but clearly different groups, while values below 0.25 are not separable (Clarke and Gorley, 2001). The contributions of macroinvertebrate taxa to within group similarity and between group dissimilarity were calculated using the SIMPER procedure in Primer.

The influence of explanatory variables on taxon assemblages was investigated through the BVSTEP procedure in the Primer package and by Canonical Correspondence Analysis (CCA) using the Canoco computer package (Canoco for Windows 4.54, ter Braak and Smilauer, 2006). Forward selection was applied in CCA to determine which variables made a significant contribution $(p<0.05)$ to explaining variance in the species data, as tested using Monte Carlo permutation test (999 permutations).

These two approaches examine taxon-environment relationships in contrasting ways and were thus employed to provide a more rigorous examination of these possible re- lationships. The BVSTEP procedure compares the ranked similarities of pairwise comparisons of samples when they are characterised by biotic assemblages with the rank similarities of the same pairwise comparisons when samples are characterised by subsets of environmental data (Clarke and Warwick, 1994). The method makes few assumptions regarding the taxon responses to environmental variables (Quinn and Keough, 2002), making it a robust test of speciesenvironment relationships; however, relationships between individual taxa and environmental variables are not directly examined. In contrast, CCA is an ordination procedure in which ordination axes are constrained to be linear combinations of environmental variables (ter Braak, 1986). It assumes unimodal responses of taxa to environmental variables (ter Braak, 1986), which may not always be the case; however, the method simultaneously examines the relationship between environmental variables and samples and taxa (Quinn and Keough, 2002) and so has the potential to provide greater insight into taxon-environment relationships.

\section{Results}

\subsection{Hydraulic conditions}

Downstream near-bed velocity $(V x)$ across all patches ranged from 0 to $97 \mathrm{~cm} \mathrm{~s}^{-1}$ (Table 2) while velocities in the transverse $(V y)$ and vertical $(V z)$ directions were lower by comparison (Table 2). In contrast, the highest levels of turbulence were recorded in the vertical direction $(\sigma V z)$, with turbulence in the transverse direction $(\sigma V y)$ generally 
Table 2. Summary statistics for near-bed hydraulic variables across all patches $(n=30)$. All variables based on velocity readings in $\mathrm{cm} \mathrm{s}^{-1}$ recorded over $60 \mathrm{~s}$ periods.

\begin{tabular}{llllll}
\hline Variable & Abbreviation & Mean & Median & Maximum & Minimum \\
\hline Downstream velocity & $V x$ & 26.64 & 20.90 & 97.02 & .01 \\
Transverse velocity & $V y$ & 1.15 & .57 & 26.65 & -19.40 \\
Vertical velocity & $V z$ & 1.20 & -.17 & 29.59 & -12.09 \\
Variance in downstream velocity & $\sigma V x$ & 17.73 & 15.25 & 74.02 & .37 \\
Variance in transverse velocity & $\sigma V y$ & 7.86 & 7.37 & 23.95 & .61 \\
Variance in vertical velocity & $\sigma V z$ & 28.89 & 21.38 & 108.73 & 4.16 \\
\hline
\end{tabular}

lowest and downstream turbulence $(\sigma V x)$ intermediate $(\mathrm{Ta}-$ ble 2). $V x$ varied significantly across flow types (df 5, $F=48.6, p<0.001$ ) with the highest values being recorded within CF patches and the lowest in NPF patches (Fig. 2a). Post-hoc pair-wise comparison showed that downstream velocity differed significantly across all flow type combinations $(p<0.001)$ except for the USW-BSW pairing and all combinations of NPF, SST and RF. Froude numbers were also significantly different across flow types (df $5 F=29.4, p<0.001$ ) (Fig. 2b). Post-hoc comparisons show that Froude numbers in CF were significantly higher than all other flow types while Froude numbers in BSW were significantly higher than RF, SST and NPF (Fig. 2b).

In contrast, neither $V y$ nor $V z$ differed significantly across flow types (Fig. 2c and d). Near-bed turbulence (sum of the $\sigma \mathrm{V}$ in all directions) also differed significantly across flow types $(F=5.03 p=0.003)$. Highest values occurred in BSW and lowest in NPF (Fig. 2e). Post-hoc tests show that this difference is driven by the differences between the near-bed turbulence of BSW patches and that of NPF $(p=0.01)$ and SST $(p=0.015)$.

The hydraulic character (combining $V x, V y, V z, \sigma V x$ $\sigma V y \sigma V z$, Froude number and depth) of the flow types is significantly different, with all pair-wise comparisons except for the NPF-SST and SST-RF pairings showing clear and significant separation (Figs. 3a and 4).

\subsection{Substratum character}

A strong relationship between flow type and the textural character of the river bed substratum was noted. The highest cover of silt and clay and sand occurred in NPF areas, while pebbles were most abundant in RF patches. Larger substratum particles, cobble, boulders and bedrock were most abundant in USW, BSW and CF areas respectively. Macrophytes occurred in 4 of the 5 replicate patches for both NPF and SST. They were also found in a single USW patch, but were not recorded in any other flow types. Filamentous green algae were identified in at least one replicate of each flow type except for SST. Biofilm cover was recorded in every patch. As for near-bed hydraulic character, there were significant dif- ferences in the overall quality of the substratum across flow types (Fig. 3b), and all pairwise tests except the NPF-SST and RF-USW pairings were significantly different (Fig. 4).

\subsection{Macroinvertebrates}

A total of 46 families and 3 subfamilies were recorded in the 30 samples. Nematoda and Oligochaeta were not identified beyond class. Families belonging to Ephemeroptera, Diptera and Tricoptera were the most common.

The median number of taxa and abundance of individuals by flow type were highest in RF and USW areas and lowest in NPF areas (Fig. 5); however, between flow type differences were only significant for the number of taxa $(F=3.422$, $p=0.018$ ). Post-hoc tests of pair-wise differences showed that the number of taxa were significantly lower in SST than in RF ( $p=0.009)$ and USW ( $p=0.013)$. Weak but significant relationships were detected between the number of taxa and $V x$ (Fig. 6a) and turbulence (Fig. 6b).

There were strong patterns in the distribution of macroinvertebrate functional feeding groups across flow types. Overall, densities of filter feeders were highest at intermediate to high near-bed $V x$ (Fig. 7) with common filterer taxa, such as Hydropsychidae and Simuliidae being more abundant in USW, BSW and CF patches. Predator and shredder densities were negatively correlated with near-bed $V x$, (Fig. 7) and, with the exception of Tipulidae, were rare in USW, BSW and $\mathrm{CF}$ patches. Gatherer/collector densities showed no relationship with $V x$ overall, although individual taxa did exhibit preferences for surface flow types. For example, Caenidae and Chironominae were most abundant in NPF, SST and RF patches, while Baetidae, Conoesucidae, Orthocladinae and Philopotamidae favoured USW, BSW and CF patches. Similarly, scraper densities were not strongly related to $V x$, although Ancylidae and Pyralidae were more abundant in BSW patches.

Macroinvertebrate assemblages within each surface flow type are clearly separated (Fig. 3c) and significantly different (Global $R=0.514, p=0.001$ ). Pair-wise comparisons show that only the BSW-CF, BSW-USW, NPF-SST and RFUSW pairings were not significantly different (Fig. 4). The 

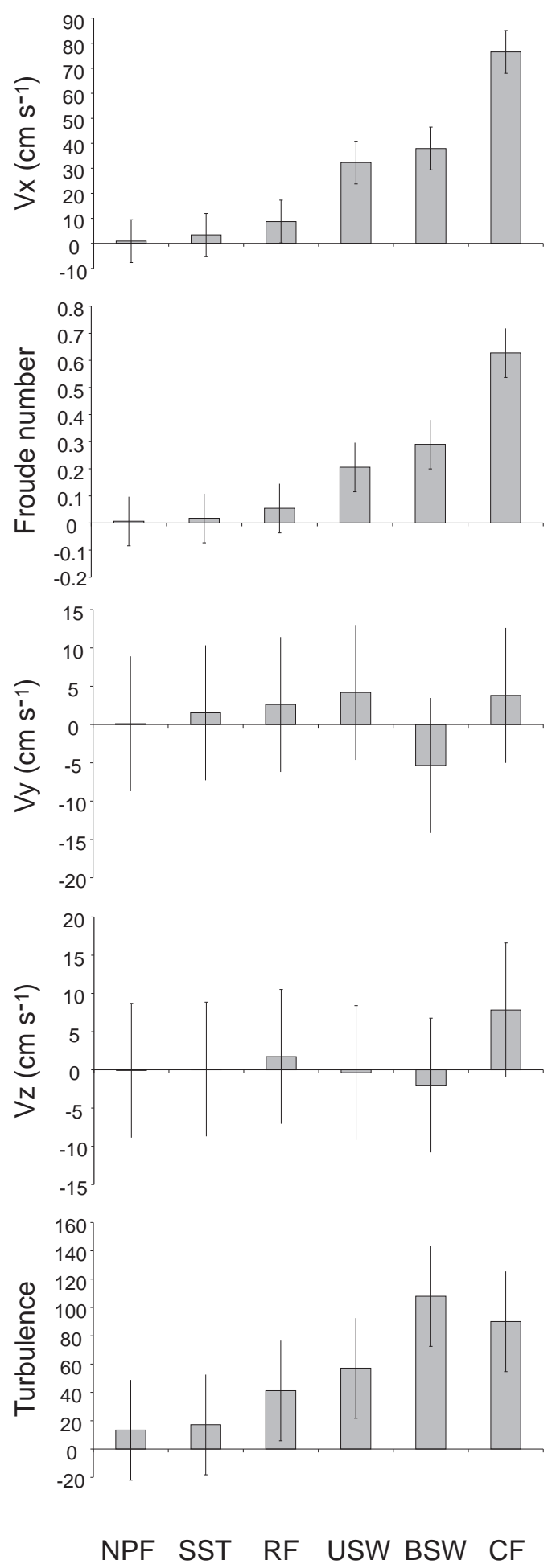

Fig. 2. Estimated marginal means for (a) Downstream velocity $(V x)$, (b) Froude number (c) Transverse velocity $(V y)$, (d) Vertical velocity $(V z)$, and (e) Turbulence, by surface flow type. Error bars indicate the $95 \%$ confidence intervals.

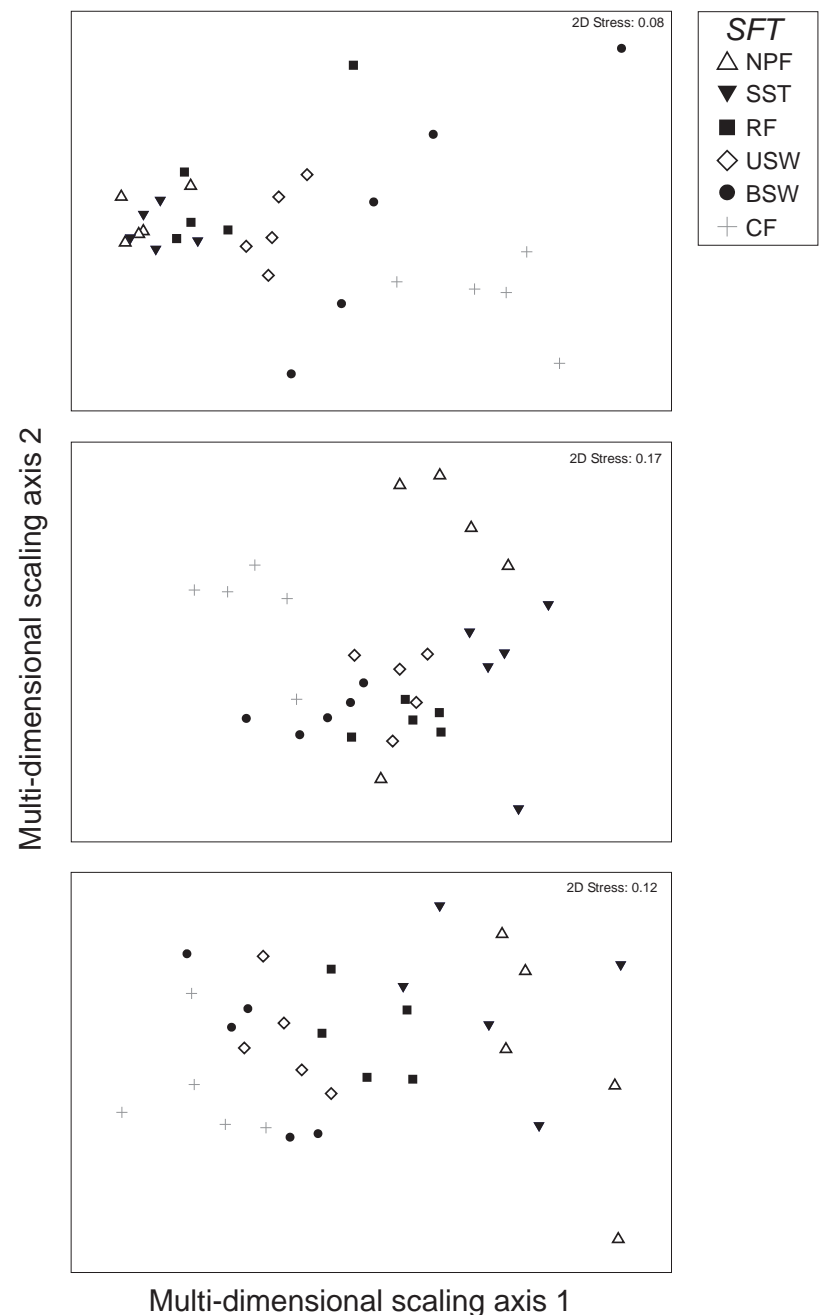

Fig. 3. Lowest stress 2-D solutions of the non-metric MultiDimensional Scaling ordinations carried out on matrices of (a) Gower similarity measures using hydraulic variables, (b) Gower similarity measures using river-bed substratum variables, and (c) Bray-Curtis similarity measures using macroinvertebrate assemblages. Samples classed by surface flow types. 


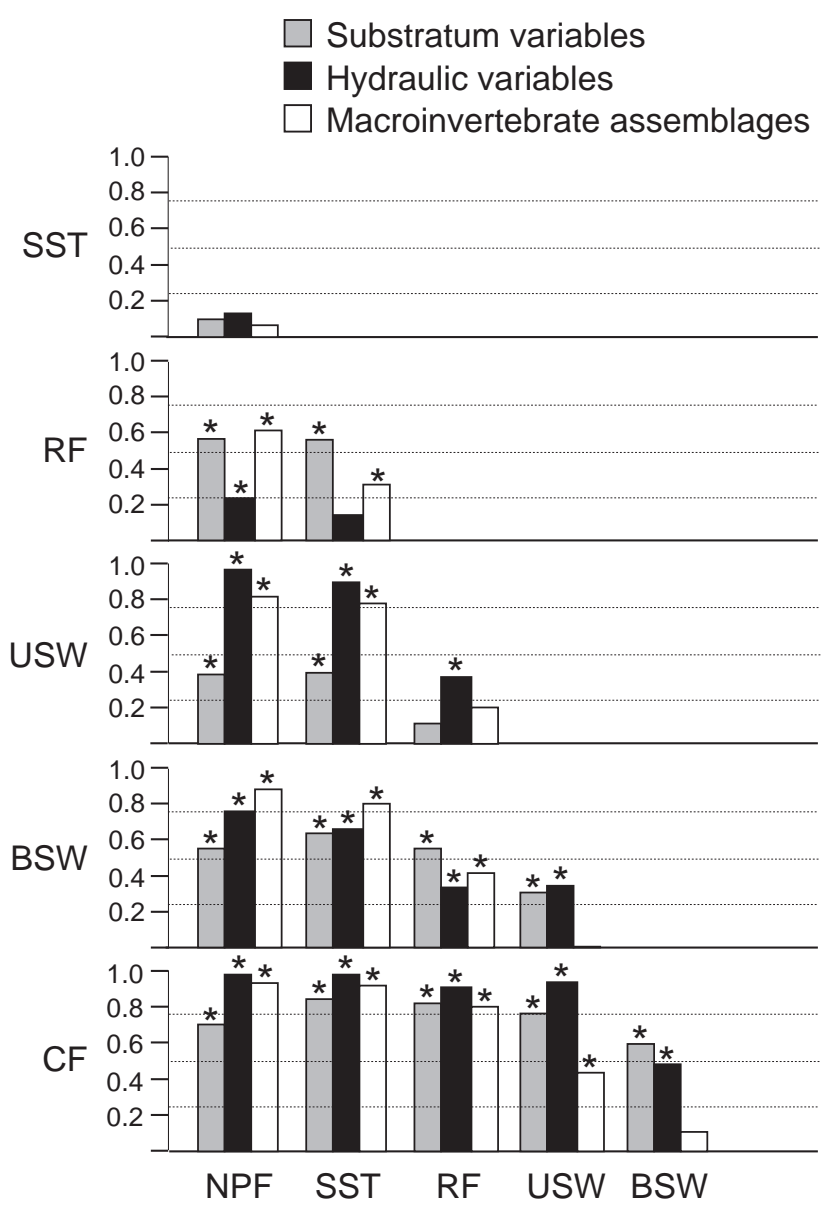

Fig. 4. $R$ values (on Y-axes) for pair-wise comparisons of groups for substratum, hydraulic, and macroinvertebrate assemblage characterisations of surface flow types. $R$ values in excess of 0.75 indicate groups are well separated, values between 0.5 and 0.75 indicate overlapping but clearly different groups, while values below 0.25 are not separable (Clarke and Gorley, 2001). Statistically significant differences are indicated by $*$.

results of SIMPER (Table 3) show that the differences between surface flow types were most strongly driven by four key taxa: Simuliidae, which were most common in BSW and USW patches; Leptophlebidae, which, while present across all flow types, peaked in RF, USW and BSW patches; Baetidae, which was also present across all flow type but peaked in USW, BSW and CF patches; and Chironominae, which were most abundant in SST patches. Among the less common taxa, Caenidae were most abundant in SST patches, Hydropsychidae and Glossosomatidae were most common in RF and USW patches, and Tanypodiinae were most common in NPF patches.
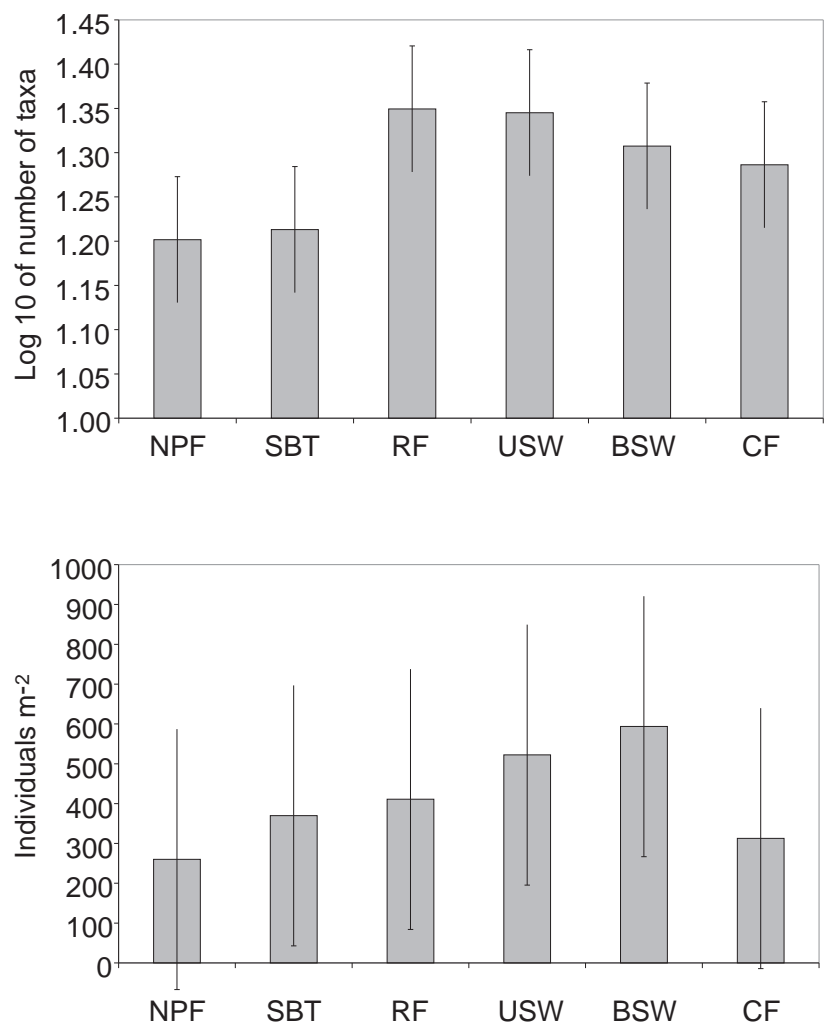

Fig. 5. Estimated marginal means for (a) Log 10 of the number of taxa, and (b) density of individuals by surface flow type.

3.4 Relationships between macroinvertebrate assemblages and environmental variables

Correlations derived using BVSTEP show the strongest correlation for combinations of physical variables was derived using a combination of mean water depth, patch size, $\sigma V y$, $V x, \%$ sand and $\%$ silt and clay (Table 4). Correlations using subsets of near-bed hydraulic variables alone and nonhydraulic variables alone were lower (Table 4).

Similar results are obtained using CCA with $V x, \%$ sand, macrophyte cover, water depth, $\%$ silt and clay and patch area each exerting a significant independent influence on the variance in assemblage data (Table 5). In combination, these variables explain $43 \%$ of the variation in macroinvertebrate distribution. When only near-bed hydraulic variables are considered, only $V x$ and $\sigma V y$ were found to make significant, independent contributions to assemblage variation, explaining roughly $22 \%$ of assemblage variation. 
Table 3. Results of SIMPER analysis showing the \% contributions of taxa to dissimilarities between the macroinvertebrate assemblages of surface flow types for the pairwise comparisons shown by ANOSIM to be significant. Only taxa contributing $>5 \%$ to the total dissimilarity between flow types are listed.

\begin{tabular}{|c|c|c|c|c|c|c|c|c|c|c|c|c|c|c|c|c|}
\hline & & NPF & $\mathrm{RF}$ & & & SST & $\mathrm{RF}$ & & & & & & & & & \\
\hline & Taxon & $\mathrm{Av} \mathrm{Ab}$ & $\mathrm{Av} \mathrm{Ab}$ & Cont $\%$ & Taxon & $\mathrm{Av} \mathrm{Ab}$ & $\mathrm{Av} \mathrm{Ab}$ & Cont $\%$ & & & & & & & & \\
\hline \multirow[t]{8}{*}{ RF } & Leptophlebiid. & 6.04 & 10.69 & 8.82 & Chironominae & 9.4 & 3.94 & 8.67 & & & & & & & & \\
\hline & Glossosomatid. & 0 & 6.66 & 8.65 & Leptophlebiid. & 5.45 & 10.69 & 8.42 & & & & & & & & \\
\hline & Hydropsychid. & 0 & 6.05 & 8.07 & Glossosomatid. & 1.05 & 6.66 & 8.15 & & & & & & & & \\
\hline & & & & & Hydropsychid. & 2.78 & 6.05 & 7.71 & & & & & & & & \\
\hline & & & & & Caenidae & 7.25 & 3.77 & 5.56 & & & & & & & & \\
\hline & & NPF & USW & & & SST & USW & & & & & & & & & \\
\hline & Taxon & $\mathrm{Av} \mathrm{Ab}$ & $\mathrm{Av} \mathrm{Ab}$ & Cont $\%$ & Taxon & $\mathrm{Av} \mathrm{Ab}$ & $\mathrm{Av} \mathrm{Ab}$ & Cont $\%$ & & & & & & & & \\
\hline & Simuliidae & 0 & 9.25 & 9.9 & Simuliidae & 0 & 9.25 & 9.91 & & & & & & & & \\
\hline \multirow{7}{*}{ USW } & Leptophlebiid. & 6.04 & 11.13 & 6.95 & Chironominae & 9.4 & 1.61 & 8.93 & & & & & & & & \\
\hline & Hydropsychid. & 0 & 5.88 & 6.94 & Caenidae & 7.25 & 0.78 & 7.44 & & & & & & & & \\
\hline & Baetidae & 2.61 & 8.07 & 6.16 & Leptophlebiid. & 5.45 & 11.13 & 6.8 & & & & & & & & \\
\hline & Glossosomatid. & 0 & 4.53 & 5.36 & Baetidae & 1.9 & 8.07 & 6.68 & & & & & & & & \\
\hline & & & & & Hydropsychid. & 2.78 & 5.88 & 6.1 & & & & & & & & \\
\hline & & NPF & BSW & & & SST & BSW & & & $\mathrm{RF}$ & BSW & & & & & \\
\hline & Taxon & $\mathrm{Av} \mathrm{Ab}$ & $\mathrm{Av} \mathrm{Ab}$ & Cont $\%$ & Taxon & $\mathrm{Av} \mathrm{Ab}$ & $\mathrm{Av} \mathrm{Ab}$ & Cont $\%$ & Taxon & $\mathrm{Av} \mathrm{Ab}$ & $\mathrm{Av} \mathrm{Ab}$ & Cont $\%$ & & & & \\
\hline \multirow[t]{6}{*}{ BSW } & Simuliidae & 0 & 10.88 & 10.17 & Simuliidae & 0 & 10.88 & 10.31 & Simuliidae & 2.38 & 10.88 & 10.37 & & & & \\
\hline & Baetidae & 2.61 & 8.64 & 6.11 & Chironominae & 9.4 & 2.39 & 8.11 & Leptophlebiid. & 10.69 & 8.77 & 6.76 & & & & \\
\hline & Leptophlebiid. & 6.04 & 8.77 & 5.47 & Caenidae & 7.25 & 0.4 & 7.56 & Baetidae & 3.46 & 8.64 & 6.59 & & & & \\
\hline & Tanypodiinae & 5.56 & 0.48 & 5.13 & Baetidae & 1.9 & 8.64 & 6.69 & & & & & & & & \\
\hline & & NPF & $\mathrm{CF}$ & & & SST & $\mathrm{CF}$ & & & $\mathrm{RF}$ & $\mathrm{CF}$ & & & USW & $\mathrm{CF}$ & \\
\hline & Taxon & $\mathrm{Av} \mathrm{Ab}$ & $\mathrm{Av} \mathrm{Ab}$ & Cont $\%$ & Taxon & $\mathrm{Av} \mathrm{Ab}$ & $\mathrm{Av} \mathrm{Ab}$ & Cont $\%$ & Taxon & $\mathrm{Av} \mathrm{Ab}$ & $\mathrm{Av} \mathrm{Ab}$ & Cont $\%$ & Taxon & $\mathrm{Av} \mathrm{Ab}$ & $\mathrm{Av} \mathrm{Ab}$ & Cont $\%$ \\
\hline \multirow[t]{5}{*}{$\mathrm{CF}$} & Simuliidae & 0 & 7.24 & 8.36 & Chironominae & 9.4 & 1.25 & 9.1 & Leptophlebiid. & 10.69 & 3.69 & 9.7 & Leptophlebiid. & 11.13 & 3.69 & 11.81 \\
\hline & Baetidae & 2.61 & 7.8 & 6.5 & Simuliidae & 0 & 7.24 & 8.26 & Glossosomatid. & 6.66 & 2.62 & 6.94 & Simuliidae & 9.25 & 7.24 & 9.5 \\
\hline & Tanypodiinae & 5.56 & 0.2 & 5.99 & Caenidae & 7.25 & 0.6 & 7.87 & Simuliidae & 2.38 & 7.24 & 6.48 & Baetidae & 8.07 & 7.8 & 6.24 \\
\hline & Leptophlebiid. & 6.04 & 3.69 & 5.34 & Baetidae & 1.9 & 7.8 & 6.95 & Baetidae & 3.46 & 7.8 & 6.21 & Glossosomatid. & 4.53 & 2.62 & 6 \\
\hline & & NPF & & & & SST & & & & RF & & & & USW & & \\
\hline
\end{tabular}

Table 4. Spearman correlation coefficients between macroinvertebrate assemblage data and combinations of environmental variables.

\begin{tabular}{lc}
\hline Variable combination & Correlation \\
\hline All variables: & 0.774 \\
$\%$ Silt and clay, \% Sand, \% Pebble, Log 10 Patch area, Macrophyte cover, Water depth, $V x, \sigma V y$, & 0.667 \\
Non-hydraulic variables: & \\
$\%$ Silt and clay, \% Sand, Log 10 Patch area & 0.604 \\
Hydraulic variables: & \\
$V x, \sigma V y$, Water depth & \\
\hline
\end{tabular}

\section{Discussion}

4.1 Do surface flow types provide a characterisation of physical habitat relevant to macroinvertebrates?

The surface flow type patches examined in this study have distinct hydraulic, river-bed substratum, and macroinvertebrate character, suggesting that surface flow types studied, do provide a characterisation of the physical habitat relevant to macroinvertebrates. This supports the findings of other examinations of the hydraulic character of surface flow types by Newson and Newson (2000) and Padmore (1998) as well as the study by Gundy (1996) who compared macroinvertebrate assemblages and water column hydraulic conditions across surface flow types.
Although the macroinvertebrate assemblages of some flow types are not strongly separated, for example NPF from SST, RF from USW, USW from BSW, and BSW from CF, this is to be expected given the gradient of increasing hydraulic energy that is associated with the transition from NPF through to CF conditions. Viewed in these terms it can be seen that, in most cases, the macroinvertebrate assemblages of each flow type are not strongly distinguished from those of the flow types with the next highest and next lowest hydraulic energy (for example, USW from BSW and RF). The only clear break in the assemblages found in flow types along this gradient is between NPF and SST and the remaining flow types. Accordingly, it could be argued that there is little value, it terms of the capacity to predict macroinvertebrate assemblages, in separating NPF patches from SST patches in surface flow type mapping. The same cannot be said, however, for the remaining flow types examined in this study because 
Table 5. Marginal and conditional effects of the significant environmental variables in CCA. The canonical eigenvalue of each variable, $\lambda-1$, indicates the amount of species variance potentially explained by that variable alone (the marginal effect). The $\lambda$-A value indicates the increase in the sum of all canonical eigenvalues of the ordination when that variable is added sequentially (the conditional effect). At each iteration, the variable explaining the greatest amount of species variance (highest $\lambda$-A) is added. $F$ and $p$ values are based on Monte Carlo permutation tests with 999 permutations and indicate whether the variables add a significant amount to variance explained.

\begin{tabular}{lllllll}
\hline & \multicolumn{3}{c}{ Marginal effects } & \multicolumn{3}{c}{ Conditional effects } \\
\hline Variable & $\lambda-1$ & \% variance explained & $\lambda$-A & $\%$ variance explained & F-ratio & $P$ \\
\hline$V x$ & 0.24 & 15.97 & 0.24 & 15.97 & 5.32 & 0.001 \\
\% Sand & 0.18 & 12.22 & 0.12 & 8.14 & 2.89 & 0.003 \\
Macrophyte cover & 0.20 & 13.55 & 0.09 & 5.95 & 2.22 & 0.001 \\
Water depth & 0.19 & 12.61 & 0.07 & 4.73 & 1.81 & 0.008 \\
\% Silt \& clay & 0.12 & 8.12 & 0.07 & 4.59 & 1.82 & 0.045 \\
Log 10 Patch area & 0.22 & 14.84 & 0.06 & 3.85 & 1.56 & 0.047 \\
Total & & & 0.65 & 43.24 & & \\
\hline
\end{tabular}

separation of these flow types does ultimately resolve different macroinvertebrate assemblages, albeit along a gradient of "linked" assemblages.

In general, there is good agreement in the degree to which surface flow types are separated based on the three characterisations. Ten of the 15 possible comparisons showed significant differences between surface flow types for all three characterisations and one, the NPF-SST comparison, was not significant for all three. However, there are some inconsistencies, particularly involving USW and RF patches, and these may reflect the relative importance of the different drivers of invertebrate distributions across the range of surface flow types. It also illustrates the likely importance of the interactive effects of the range of physical drivers that create biotic habitat.

In the case of RF, the degree of separation from NPF and SST is lower when the surface flow types are characterised by hydraulic conditions than it is when the characterisation is based on river-bed substratum or invertebrate assemblages. This suggests that the river-bed substratum character is a more important determinant of invertebrate assemblages across these surface flow types than hydraulic character. Invertebrate assemblages of RF patches differed from both NPF and SST patches by higher abundances of Leptophlebiidae and Glossosomatidae and lower abundances of Chironominae and Caenidae. Although NPF patches were characterised by low $\%$ cobble and high $\%$ silt and clay and there is little difference in the size distribution of the substratum of RF and SST patches. Therefore the main feature separating RF from NPF and SST appears to be the absence of macrophytes within RF patches. Two conclusions can be drawn from these patterns. First, although the $\%$ of silt and clay was found to be an important driver of invertebrate distributions across the full range of surface flow types, it does not appear to strongly influence the distribution of invertebrates across NPF and SST patches. The influence of the recent high sediment loads associated with the extensive fire three years prior to sampling (Norris and Thoms, 2004) on this relationship is unknown. Second, macrophytes constitute an important component of the physical habitat template, either as a food source or refuge, for groups such as Chironominae and Caenidae. This is supported by the strong relationships between invertebrate assemblages and macrophyte cover (Tables 3 and 4).

A contrasting pattern exists for USW patches, which are more strongly separated from both NPF and SST patches when characterised by hydraulic conditions or invertebrate assemblages than when characterised by substratum quality. As for RF patches, the invertebrate assemblages of USW patches also have high abundances of Leptophlebiidae and few Chironominae and Caenidae, but are further distinguished from NPF and SST patches by higher abundances of Simulidae and Baetidae and by reduced abundances of predacious invertebrates. Both downstream velocity and turbulence are substantially higher in USW patches. The importance of flow velocity to Simulidae is well established (Fonseca and Hart, 1996; Hart and Merz, 1998); however, the reduced abundance of predators in high flow velocity flow types suggests that reduced predation pressure may also be an important factor driving invertebrate distributions across hydraulic gradients (Hart and Merz, 1998). The overall density of individuals was highest in USW and BSW.

There is also inconsistency in the degree of separation of flow types by hydraulic, river-bed substratum and macroinvertebrate assemblage character among the higher energy flow types (USW, BSW and CF). These surface flow types are not strongly separated with regard to their macroinvertebrate assemblages, despite strong separation by hydraulic conditions and river-bed substratum (Fig. 4). This indicates there is little species turn over at the upper end of the hydraulic gradient, perhaps because conditions are suboptimal for all taxa. This may reflect physical limitations of taxa with 

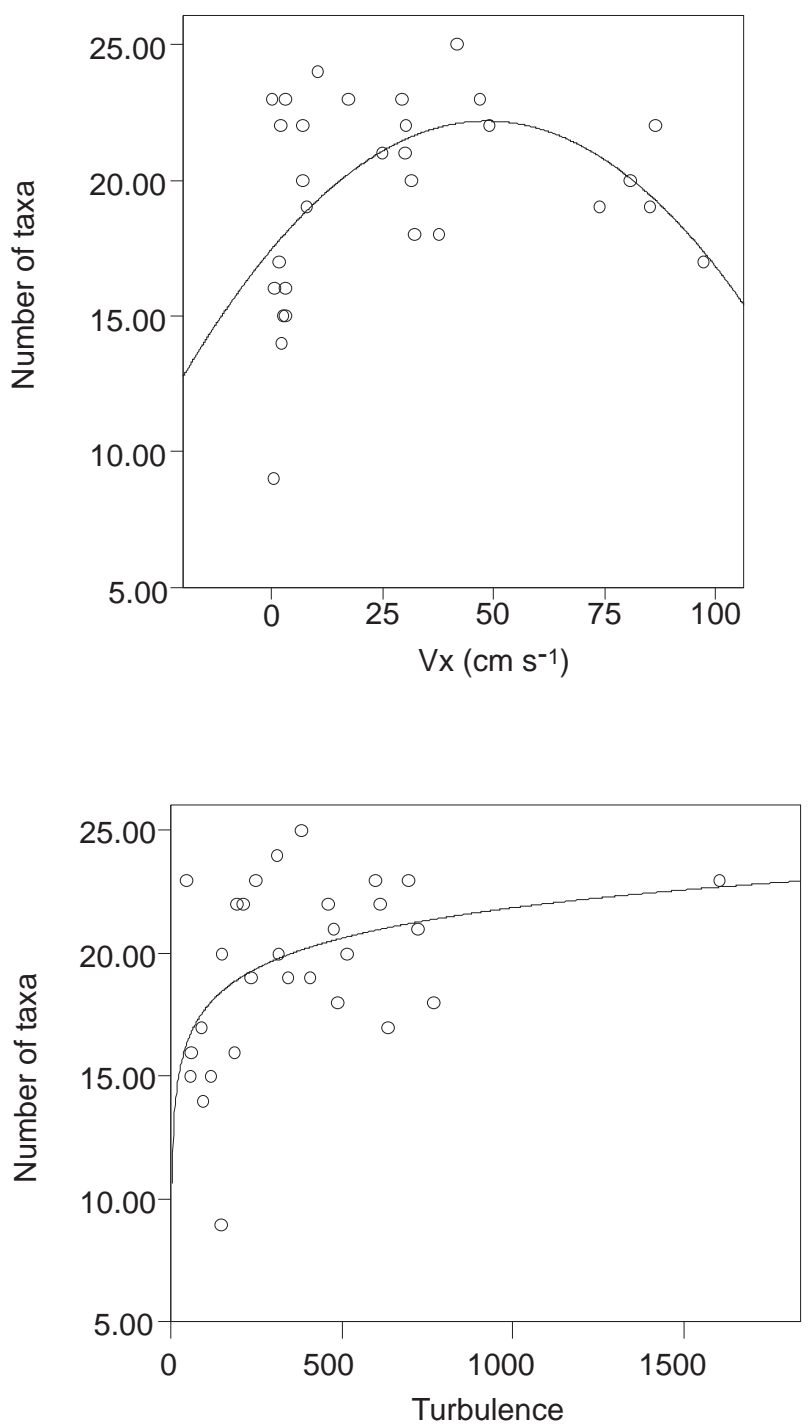

Fig. 6. Relationships between taxon number and (a) $V x$ and (b) turbulence across all patches.

regard to their capacity to cope with extreme hydraulic conditions.

4.2 To what extent do near-bed hydraulic conditions explain macroinvertebrate distributions?

The difficulties involved in establishing the independent influences of hydraulic conditions and substratum character on benthic invertebrates have been noted previously (Quinn et al., 1996; Rempel et al., 2000; Jowett, 2003). This difficulty results from both the causal relationships between hydraulic conditions and the abiotic and biotic components of the substratum (Biggs et al., 2005) and the potential for both ambient hydraulic conditions and structural features of the riverbed to influence macroinvertebrate communities (Rempel et al., 2000). This present study shows that, although there are clear interactions between near-bed hydraulic conditions and river-bed substratum character, each subset of physical variables appears to be independently important, as shown by the fact that the strongest relationships between macroinvertebrates and explanatory variables were obtained when both near-bed hydraulic conditions and other physical variables were considered (Tables 3 and 4).

The results presented here support other studies that have highlighted the importance of inferred near-bed hydraulic conditions, independent of the influence of river-bed substratum alone (Quinn and Hickey, 1994; Armitage and Cannan, 2000; Rempel et al., 2000). That these relationships are found, despite the strong interactions between river-bed substratum and hydraulic conditions, may reflect the fact that the substratum at any one location on the stream bed reflects the longer-term history of hydraulic conditions experienced at a location, in particular, the recent history of high discharge events, rather than the ambient hydraulic conditions (Beisel et al., 1998; Armitage and Cannan, 2000). Moreover, other variables independent of hydraulic character, such as catchment geology, also have the potential to influence river-bed substratum character. The additional variation in invertebrate distributions that is explained by the near-bed hydraulic variables $V x$ and $\sigma V x$ conditions implies that there is a degree of active or passive selection of hydraulic conditions by benthic invertebrates that occurs at timescales short enough to allow for this mismatch to develop (Fonseca and Hart, 2001).

At the same time, near-bed hydraulic conditions as measured in this study do not themselves provide the best predictions of invertebrate distributions. This is likely to reflect two key factors: first, the capacity of invertebrates to utilise the substratum in such a way as to avoid unfavourable conditions over small spatial scales (Jowett, 2003) and second, the reduced influence of hydraulic conditions on distributions where those conditions are within an individual's tolerance.

4.3 What components of hydraulic character exert the strongest influence on macroinvertebrate distributions?

Near-bed $V x$ is clearly the most important hydraulic variable influencing both assemblage composition and the number of taxa found in each surface flow type patch. By contrast, velocities in the transverse and vertical directions appear to have minimal influence on invertebrate distributions. Turbulence appears also to be an important factor, with turbulence in the transverse direction apparently of equal or greater importance than turbulence in the downstream direction (Table 3), despite its lower absolute magnitudes (Table 2).

The importance of turbulence to benthic macroinvertebrates has been demonstrated elsewhere. Quinn et al. (1996) introduced roughness elements upstream of artificial substrates to modify near-bed hydraulic conditions independently of substratum character. These roughness elements resulted in reduced downstream velocity and increased turbulence. The response in macroinvertebrate assemblages was for densities to decline overall, with the strongest declines 

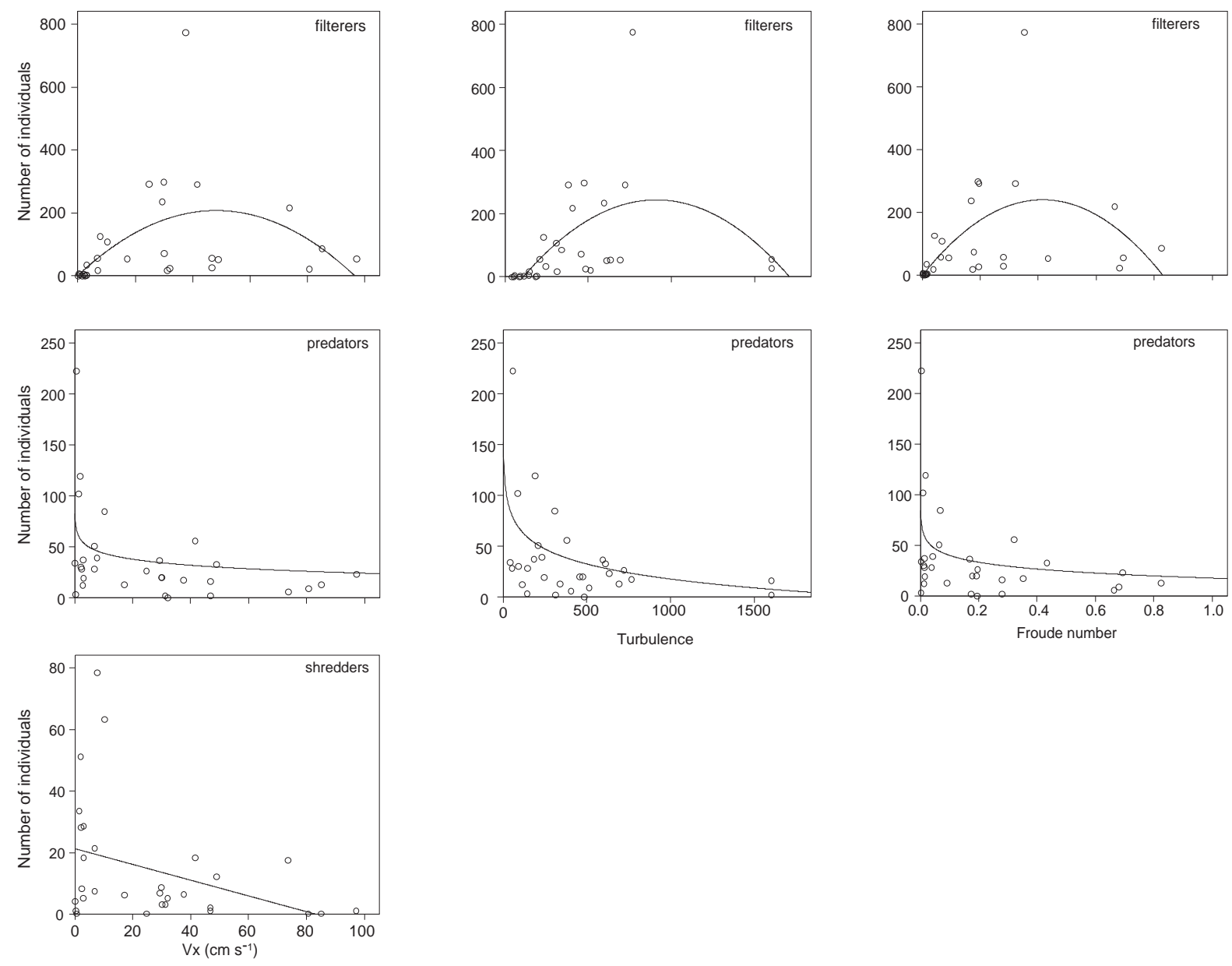

Fig. 7. Relationships between the abundances of filterer, predator and shredder functional groups and $V x$, Turbulence and Froude number across all patches.

being evident among filter-feeding animals. This pattern was attributed to reduced filter feeding efficiency under a high turbulence-low velocity regime. In particular, Quinn et al. (1996) suggest that high turbulence conditions may result in "back-washing" of material from filtering structures used by the dominant filtering taxa in the system. This process does not seem to be important in the Cotter River because the highest densities of filter-feeding organisms were found in BSW patches, which are characterised by both high $V x$ and the highest turbulence. Instead, it would seem that the importance of turbulence may reflect avoidance of high velocity and turbulence conditions by predators and shredders in combination with a preference for such conditions among filterers. This preference in turn, may reflect both a direct preference for high velocity conditions (reflecting higher feeding efficiency) and reduced predation pressure in the micro-refuges created by high flow velocities (Hart and Merz, 1998).
The reason for the particular importance of $\sigma V y$ is not clear. $V x$ is the principal flow variable controlling macroinvertebrate distribution - animals possess traits and behaviours that enable them to maintain position and move with respect to their preferred $V x$ regime (Statzner and Holm, 1989; Growns and Davis, 1994). Beyond this, the limitations in distribution may relate to individual's capacity to cope with rapid changes in velocity perpendicular to the main direction of flow. While such turbulence may not itself dislodge or disturb individuals, it may affect their capacity to cope with forces in the downstream direction by changing their orientation slightly or by lifting them into higher velocity areas above the substrate. Experimental studies are required to fully investigate the underlying causes of this pattern. 


\section{Conclusions}

This study provides further evidence of the biological importance of near-bed hydraulic conditions and of the value of measuring these conditions in a more comprehensive manner by incorporating three-dimensional velocity and turbulence measures. When these measures are used to supplement traditional measures of instream physical habitat, a more complete picture of the habitat template is provided. Further investigation of the influences of turbulence elements is needed to understand more fully the mechanisms underlying the observed patterns.

The relationships observed between surface flow types, near-bed hydraulic conditions and substrate character also support the notion that surface flow type mapping is an effective way of characterising the physical habitat template controlling macroinvertebrate distributions. Other flow characterisation methods such as those suggested by Davis and Barmuta (1989) and Young (1992) are time intensive, so surface flow type mapping may provide a valuable alternative tool for rapid assessment of physical habitat heterogeneity, and by extension, potential biological diversity and productivity. While we see no reason to assume that the findings of this study would not be generally applicable to other streams with similar levels of hydraulic heterogeneity, it is important that the relationships and patterns observed in this study are tested more broadly; in particular, testing in streams not subject to flow regulation or major catchment disturbance should be a priority.

Acknowledgements. We thank our colleagues for field work assistance and comments on earlier drafts. We also greatly appreciate the guidance and advice of John Hawking and Rhonda Butcher regarding the assignment of macroinvertebrate families to functional feeding groups. This study was supported by a research grant awarded by the University of Canberra to MCT.

Edited by: T. J. Battin

\section{References}

Armitage, P. D. and Cannan, C. E.: Annual changes in summer patterns of mesohabitat distribution and associated macroinvertebrate assemblages, Hydrol. Process., 14, 3161-3179, 2000.

Beisel, J. N., Usseglio-Polatera, P., Thomas, S., and Moreteau, J. C.: Stream community structure in relation to spatial variation: The influence of mesohabitat characteristics, Hydrobiologia, 389, 73-88, 1998.

Belbin, L. and McDonald, C.: Comparing three classification strategies for use in ecology, J. Veg. Sci., 4, 341-348, 1993.

Biggs, B. J. F., Nikora, V. I., and Snelder, T.: Linking scales of flow variability to lotic ecosystem structure and function, River Res. Appl., 21, 283-298, 2005.

Brooks, A. J., Haeusler, T., Reinfelds, I., and Williams, S.: Hydraulic microhabitats and the distribution of macroinvertebrate assemblages in riffles, Freshwater Biol., 50, 331-344, 2005.
Chessman, B.: Dietary studies of Aquatic Insects from two Victorian Rivers, Aust. J. Mar. Fresh. Res., 37, 129-146, 1986.

Clarke, K. R. and Gorley, R. N.: PRIMER v5: user manual/tutorial, PRIMER-E, Plymouth, UK, 91 pp, 2001.

Clarke, K. R. and Warwick, R. M.: Change in marine communities: An approach to statistical analysis and interpretation, National Environment Research Council, Plymouth, 144 pp., 1994.

Davis, J. A.: Boundary layers, flow microenvironments and stream benthos, in: Limnology in Australia, edited by: De Deckker, P., and Williams, W. D., CSIRO Australia, Melbourne, Australia, 293-312, 1986.

Davis, J. A. and Barmuta, L. A.: An ecologically useful classification of mean and near-bed flows in streams and rivers, Freshwater Biol., 21, 271-282, 1989.

Dyer, F. and Thoms, M. C.: Managing river flows for hydraulic diversity: An example of an upland regulated gravel bed river, River Res. Appl., 22, 257-267, 2006.

Emery, J. C., Gurnell, A. M., Clifford, N. J., Petts, G. E., Morrissey, I. P., and Soar, P. J.: Classifying the hydraulic performance of riffle-pool bedforms for habitat assessment and river rehabilitation design, River Res. Appl., 19, 533-549, 2003.

Finelli, C. M., Hart, D. D., and Merz, R. A.: Stream insects as passive suspension feeders: Effects of velocity and food concentration on feeding performance, Oecologia, 131, 145-153, 2002.

Fonseca, D. M. and Hart, D. D.: Density-dependent dispersal of black fly neonates is mediated by flow, Oikos, 75, 49-58, 1996.

Fonseca, D. M., and Hart, D. D.: Colonization history masks habitat preferences in local distributions of stream insects, Ecology, 82, 2897-2910, 2001.

Gooderham, J. and Tsyrlin, E.: The Waterbug Book: A guide to the Freshwater Macroinvertebrates of Temperate Australia, CSIRO Publishing, Collingwood, Australia, 232 pp., 2002.

Growns, I. O. and Davis, J. A.: Longitudinal changes in nearbed flows and macroinvertebrate communities in a WesternAustralian stream, J. N. Am. Benthol. Soc., 13, 417-438, 1994.

Grundy, J.: Flow types and stream ecology - putting flow types into practice. Report to the Environment Agency, Department of Geography, University of Newcastle upon Tyne, Newcastle upon Tyne, UK, 1996.

Hart, D. D. and Merz, R. A.: Predator prey interactions in a benthic stream community: A field test of flow-mediated refuges, Oecologia, 114, 263-273, 1998.

Hart, D. D. and Finelli, C. M.: Physical-biological coupling in streams: The pervasive effects of flow on benthic organisms, Annu. Rev. Ecol. S., 30, 363-395, 1999.

Jowett, I. G.: Hydraulic constraints on habitat suitability for benthic invertebrates in gravel-bed rivers, River Res. Appl., 19, 495-507, 2003.

Nikora, V. I. and Goring, D. G.: Adv measurements of turbulence: Can we improve their interpretation?, J. Hydraul. Eng.-ASCE, 124, 630-634, 1998.

Padmore, C. L.: The role of physical biotopes in determining the conservation status and flow requirements of british rivers, Aquatic Ecosystem Health \& Management, 1, 25-35, 1998.

Quinn, G. P. and Keough, M. J.: Experimental design and data analysis for biologists, Cambridge University Press, Cambridge, UK, 537 pp., 2002.

Quinn, J. M. and Hickey, C. W.: Hydraulic parameters and benthic invertebrate distributions in 2 gravel-bed New Zealand rivers, 
Freshwater Biol., 32, 489-500, 1994.

Quinn, J. M., Hickey, C. W., and Linklater, W.: Hydraulic influences on periphyton and benthic macroinvertebrates: Simulating the effects of upstream bed roughness, Freshwater Biol., 35, 301-309, 1996.

Reid, M. A., Thoms, M., and Dyer, F.: Effects of spatial and temporal variation in hydraulic conditions on metabolism in cobble biofilm communities in an Australian upland stream, J. N. Am. Benthol. Soc., 25, 756-767, 2006.

Rempel, L. L., Richardson, J. S., and Healey, M. C.: Macroinvertebrate community structure along gradients of hydraulic and sedimentary conditions in a large gravel-bed river, Freshwater Biol., 45, 57-73, 2000.

Robson, B. J., Chester, E. T. and Davis, J. A.: Manipulating the intensity of near-bed turbulence in rivers: effects on benthic invertebrates, Freshwater Biol. 42, 645-653, 1999.
Statzner, B. and Holm, T. F.: Morphological adaptation of shape to flow: Microcurrents around lotic macroinvertebrates with known Reynolds numbers at quasi-natural flow conditions, Oecologia, 78, 145-157, 1989.

ter Braak, C. J. F.: Canonical correspondence analysis: A new eigenvector technique for multivariate direct gradient analysis, Ecology, 67, 1167-1179, 1986.

ter Braak, C. J. F. and Smilauer, P.: Canoco reference manual and user's guide to Canoco for Windows (version 4), Centre for Biometry, Wageningen, The Netherlands, 351 pp., 1998.

Warwick, R. M. and Clarke, K. R.: Increased variability as a symptom of stress in marine communities, J. Exp. Mar. Biol. Ecol., 172, 215-226, 1993.

Young, W. J.: Clarification of the criteria used to identify near-bed flow regimes, Freshwater Biol. 28, 383-391, 1992. 